\title{
The prevalence of colour vision deficiency, parent-reported, and child reported difficulties among 10- to 16-year-old school children in the Galle education zone, Sri Lanka
}

\author{
Karunanayake $A^{1}$, Weerasuriya MA ${ }^{2}$, Wijekoon WMCD ${ }^{3}$ \\ ${ }^{I}$ Department of Physiology, Faculty of Medicine, University of Ruhuna, Galle, Sri Lanka. \\ ${ }^{2}$ Teaching Hospital Karapitiya, Galle, Sri Lanka. \\ ${ }^{3}$ Department of Zoology, Faculty of Science, University of Ruhuna, Matara, Sri Lanka. \\ Correspondence: Prof.Amaranath Karunanayake \\ e-mail: amaranathk@med.ruh.ac.lk \\ (D) https://orcid.org/0000-0001-5836-6329 \\ Submitted on 22.05.2021 and accepted for publication on 01.06.2021
}

\begin{abstract}
Introduction: X-linked recessive hereditary disorders is the main cause of colour vision deficiency (CVD). The prevalence of CVD varies from race to race. This study was conducted to determine the prevalence of CVD among 10- to 16-year-old school children in Galle educational zone, Sri Lanka.

Methods: A total of 566 students (males $=260$ ) were examined with Ishihara pseudo-isochromatic colour plates. The parental questionnaire was used to obtain a family history of CVD, the ability of the child to select coloured objects and past medical history. Both parents and children were subjected to the same questions separately on their ability to differentiate coloured objects during activities of day-to-day life. Parents reported difficulties and child reported difficulties in colour perception were compared with 32 healthy age matched controls who were selected from the same school of the respective CVD patients.

Results: The overall prevalence of CVD was $1.4 \%$ with a prevalence of $3.1 \%$ for males. Patients were detected in all three main ethnic groups of Sri Lanka (Six Sinhala, one Tamil and one Muslim boy). All affected children had negative histories of previous systemic and ocular disease or chronic use of medications. The visual acuity and the ocular fundi were normal in all affected children. Seven (1.23\%) had deuteranomaly, while one $(0.17 \%)$ had protanomaly. Seventy five percent $(06)$ of the parents of affected children were unaware of their child's defect, while only one reported a positive family history. Parental reporting of difficulties in selecting coloured objects in the child's day-to-day activities was not significantly associated with the defect $(p>0.05)$. Children with CVD had reported difficulties in identifying colour objects in television/computer programmes and separation of cooked from uncooked food $(p<0.05)$. Fifty percent of the affected children were intimidated by their friends for their difficulties.
\end{abstract}

Conclusions: CVD is not uncommon in the Galle education zone, Sri Lanka. The affected children face difficulties in their day-to-day life due to their defects.

Key words: Colour blindness, Colour vision deficiency, Ishihara pseudo-isochromatic colour plates, SriLanka. 


\section{Introduction}

In various stages of human evolution, colour perception has played a vital role in survival. In primitive African tribes, difficulties in colour identification were a disadvantage for hunters and deprived their ability to identified poisonous fruits $(1,2)$. In the modern world, colour perception may not play a significant role in survival. However, colour perception affects various aspects of life, from childhood to adulthood. The implications of colour perception extend across sports, driving, educational activities, occupation, and personal safety. A survey of dictionaries of the languages spoken by the populations for which red-green CVD data are available confirmed that distinct words for "blue" are also rare near the equator and more common at higher latitudes (3). This signifies the evolutionary, physiological pressure of CVD in regional languages and literature.

The inability to perceive specific colours in their pure or 'natural' form is defined as colour vision deficiency (CVD) or rather loosely as colour blindness. In 1794, English chemist John Dalton presented a paper on colour vision deficiency titled "Extraordinary Facts Relating to the Vision of Colors", which described his problems in identifying colours (4). The condition became more widely known after a fatal train crash in Sweden in 1875 that is believed to have been partly caused by the driver's colour vision deficiency (5).

$\mathrm{X}$-linked recessive hereditary disorder is the main cause of CVD resulting in defective development of one or more of the three sets of the cone cells which sense colour. Female carriers or male sufferers are not generally prevented from reproduction. Therefore, evolutionary pressure against the gene is very slight. Contemporary society presents them with increasing problems because the colour is now so widely used in the modern world. All people with abnormal colour vision, except for a few mildly affected deuteranomaly, report that they experience problems with perceiving colour in everyday life, educational activities and occupation $(6,7)$. CVD is considered as a handicap for certain occupations, including the practice of medicine (8). Acquired CVD is reported as side effects of drugs and as a complication of diseases (9).
The prevalence of CVD is approximately $8 \%$ in white men and $0.7 \%$ in white women (10). Most individuals with congenital CVD have the defective perception of red and green (10). CVD prevalence in Asian and African countries are lower than that in the west (10). However, there are no large scale studies in Sri Lanka except a few on selected groups $(11,12)$.

The main objective of the study was to determine the prevalence of CVD in school children of 10-16 year age group in the Galle education zone, Sri Lanka and to determine the effects of colour vision deficiency on education and day-to-day life.

\section{Methods}

The study was conducted among school children aged between 10-16 years in two randomly selected schools in the Galle education zone.

The sample size for the study was calculated according to the Lowanga and Lemeshow formula (Lowanga and Lameshow 1991). The minimum required sample size for the study was obtained using single proportion formula by taking the prevalence of CVD as $2.5 \%$ from a previous study based on university students in Sri Lanka (10).

The estimated sample size was 149. However, considering the low prevalence of CVD in Asian countries, it was decided to recruit a minimum of 500 children.

Before undertaking a colour vision test, all children underwent visual acuity test and ophthalmoscope examination of the ocular fundus was done by medical officer trained in ophthalmic procedures and a visual acuity of $6 / 6$ in both eyes was considered as the normal. The test was conducted using Snellen tumbling 'E' chart at $6 \mathrm{~m}$ from the observer under monocular viewing during daylight hours. The right eye was tested first, and then the left one followed. The children with refractive errors were excluded from the study. Written informed consent from parents and assent from children were obtained to participate in the study.

A brief questionnaire was used on parents of children were selected for the study to obtain basic details on ability of their child to select coloured objects, family history of CVD and past medical history. 
Both parents and children were subjected to the same questions separately on their ability to differentiate coloured objects during activities of day-to-day life (Table 2). The parent reported and child reported difficulties were compared.

Their colour vision was checked by using Ishihara pseudo-isochromatic colour plates (36 colour plates). The child was instructed to read the numerals in Ishihara pseudo-isochromatic colour plates within three seconds. The plates were held at a distance of $75 \mathrm{~cm}$ perpendicular to the line of sight under daylight illumination. The Ishihara test (36-plate version) was considered passed if the first 15 plates were identified without an error, uncertainty or hesitation spending less than 3 seconds per plate. Individual errors on three or more of the numeral plates were considered as CVD. Failure to see the red numeral was indicated the Protan and failure to see the red-purple numeral was indicated the Deutan in plates 22-25.

Parents reported difficulties and child reported difficulties in colour perception were compared with 32 healthy age matched controls who were selected from the same school of the respective CVD patients.

The ethical clearance for the study was obtained from the Ethics Review Committee of the Faculty of Medicine, University of Ruhuna.

\section{Results}

A total of 566 students (260 males) whose visual acuity and ocular fundus were normal were recruited for the study. The overall prevalence of CVD was $1.4 \%$ with a prevalence of $3.1 \%$ for males (Table 01). Six Sinhala, one Tamil and one Muslim boy had CVD. All affected children had negative histories for previous systemic and ocular diseases or chronic use of medications. Seven $(1.23 \%)$ had deuteranomaly, while one $(0.17 \%)$ had protanomaly.

When compared with healthy children, children with CVD had reported a significant difference in ability to separate cooked from uncooked food and identifying colours in T.V./computer colour setting (Table 2)

Seventy five percent (06) of the parents of the affected children were unaware of their child's defect, while one reported a positive family history. There was no significant difference in parental reporting of difficulties in selecting coloured objects in the child's day-to-day activities between the two groups $(p>0.05)$ (Table 3$)$.

Table 1: Comparison of the distribution of CVD with the different Asian population

\begin{tabular}{|c|c|c|c|c|c|c|}
\hline \multirow{3}{*}{$\begin{array}{l}\text { Country } \\
\text { Current study }\end{array}$} & \multirow{3}{*}{$\begin{array}{c}\begin{array}{l}\text { Sample } \\
\text { size }\end{array} \\
566\end{array}$} & \multirow{3}{*}{\begin{tabular}{|c|}
$\begin{array}{c}\text { No of } \\
\text { males }\end{array}$ \\
260 \\
\end{tabular}} & \multirow{3}{*}{$\begin{array}{l}\begin{array}{l}\text { No of CVD } \\
\text { males }\end{array} \\
08\end{array}$} & \multirow{2}{*}{$\begin{array}{l}\text { Prevalence of } \\
\text { CVD }\end{array}$} & \multicolumn{2}{|c|}{ CVD type in males } \\
\hline & & & & & Protanomaly & Deuteranomaly \\
\hline & & & & $\begin{array}{l}\text { Males }=3.1 \% \\
\text { Female }=0.0 \%\end{array}$ & $2.69 \%$ & $0.38 \%$ \\
\hline $\begin{array}{l}\text { Indian } \\
(13)\end{array}$ & 1028 & 545 & 41 & $\begin{array}{l}\text { Male }=7.52 \% \\
\text { Female }=0.83 \%\end{array}$ & $1.1 \%$ & $3.67 \%$ \\
\hline $\begin{array}{l}\text { Tibetans } \\
\text { (14) }\end{array}$ & 2010 & 1210 & 51 & $\begin{array}{l}\text { Male }=4.2 \% \\
\text { Female }=0.0 \%\end{array}$ & $19.6 \%$ & $43.13 \%$ \\
\hline $\begin{array}{l}\text { Nepalese } \\
(15)\end{array}$ & 964 & 474 & 18 & $\begin{array}{l}\text { Male }=3.9 \% \\
\text { Female }=0.0 \%\end{array}$ & $17 \%$ & $33 \%$ \\
\hline
\end{tabular}


Table 2: Difficulties in identifying coloured objects reported by children

\begin{tabular}{lccc}
\hline $\begin{array}{l}\text { Activity in everyday life affected due to inability } \\
\text { of identification of colour }\end{array}$ & $\begin{array}{l}\text { \% of CVD with } \\
\text { difficulties } \\
\text { (n=8) }\end{array}$ & $\begin{array}{l}\text { \% of normal } \\
\text { with difficulties } \\
(\mathbf{n = 3 2})\end{array}$ & $\boldsymbol{p}^{*}$ \\
\hline Q1. Cloth colour & $12.5 \%$ & $3.1 \%$ & 0.364 \\
Q2. Natural colour & 12.5 & 0 & 0.200 \\
Q3. Colour difference of cooked and uncooked food & $50 \%$ & $0.00 \%$ & 0.001 \\
Q4. Colour in sports activities & $25 \%$ & $6.3 \%$ & 0.960 \\
Q5. TV / computer colour setting & $50 \%$ & $15.6 \%$ & 0.015 \\
Q6. Skin colour & 0 & $3.1 \%$ & 0.800 \\
Q7. Coloured chart & $12.5 \%$ & 0 & 0.200 \\
Q8. Colours used in hobbies & $12.5 \%$ & $3.1 \%$ & 0.364 \\
Q9. Bullied due to difficulties in colour identification & $50 \%$ & 0 & 0.001 \\
\hline
\end{tabular}

* Fisher's exact test

Table 3: Difficulties in identifying coloured objects reported by parents

\begin{tabular}{lclc}
\hline $\begin{array}{l}\text { Activity in everyday life affected due to inability } \\
\text { of identification of colour }\end{array}$ & $\begin{array}{l}\text { \% of CVD with } \\
\text { difficulties } \\
(\mathbf{n}=\mathbf{8})\end{array}$ & $\begin{array}{l}\text { \% of normal } \\
\text { with difficulties } \\
(\mathbf{n}=\mathbf{3 2})\end{array}$ & $\boldsymbol{p}^{*}$ \\
\hline Q1. Cloth colour & 0 & 3.1 & 0.793 \\
Q2. Natural colour & 0 & 3.1 & 0.793 \\
Q3. Colour difference of cooked and uncooked food & 37.5 & 9.8 & 0.082 \\
Q4. Colour in sports activities & 12.5 & 3.1 & 0.364 \\
Q5. Skin colour & 0 & 6.3 & 0.623 \\
\hline
\end{tabular}

* Fisher's exact test

\section{Discussion}

This population-based, cross-sectional study has reported the overall prevalence of CVD as $1.4 \%$ ( 8 boys) with the prevalence of $3.1 \%$ for males in the selected sample of school children in Galle district, Sri Lanka among the 10-16 year age group. Seven males $(1.23 \%)$ had deuteranomaly, while one male $(0.17 \%)$ had protanomaly. CVD patients have reported difficulties in some day-to-day activities and colour discrimination.

Geographical variations in CVD distributions emphasized the importance of determining the prevalence of CVD in the country. A geographical review of the published literature confirmed that red-green CVD is rare near the equator and more prevalent at higher latitudes (10). In northern Europe, a reasonable consensus figure for all forms of CVD is about $8 \%$ in males (10), whereas the prevalence is nearer to $2 \%$ among Blacks, Aboriginal Australians, and Native Americans (10). To our knowledge, no previous populationbased, cross-sectional study has investigated the prevalence of CVD in the Sri Lankan population. The overall prevalence and the male prevalence 
in our study are similar to the previous two studies done among Sri Lankan university students $(11,12)$. However, congenital CVD is a common condition in Western countries which affected $8 \%$ of males and $0.4 \%$ of females (10). Several theories explained the racial difference in the prevalence. The theory of relaxation of natural selection published in 1962 is the oldest theory (1). According to that, CVD was a disadvantage for hunters in the African population. The low prevalence of CVD in primitive populations was related to the deaths due to the consumption of erroneously identified poisonous fruits by the affected people (2). However, natural selection pressure was minimal in agriculturalbased European populations. Therefore, there is high CVD prevalence in western hemispheres. Furthermore, CVD patients with superior luminance discrimination in mesopic light levels had advantages over the trichromats in the western hemisphere with longer hours of twilight (16). The Hardy-Weinberg Law is used to explain the distribution of CVD in large populations. However, it is difficult to attribute the low prevalence reported in this study and studies done in other Asian countries to any of the theories. Even with this sample size, we have detected CVD patients in all main ethnic groups of Sri Lanka. Despite the fact that we did not analyse their pedigrees, the importance of the large population-based study to define the ethnicity-specific prevalence of CVD in Sri Lanka is emphasized.

Difficulties related to CVD have been reported from childhood to adulthood (7). The affected areas extend across education, occupation, sports and safety concerns. Discrimination and bullying are raised as a difficulty, especially in children. CVD patients develop adaptive strategies to minimize the effects of CVD. The unaffected visual memory may help the strength of their adaptive strategies (17). However, psychophysical studies have proposed compensatory advantages associated with CVD. Morgan et al. have concluded that colour can interfere with segregation based upon texture and that dichromats are less susceptible to such interference (18). Further, it has been argued that CVD leads to better spatial resolution and visual acuity (19). The dichromats seem to be able to compensate for their reduced chromatic information range when viewing complex natural scenes because their visual memory for coloured scenes is not impaired, as compared with that of trichromats (20).

The awareness of their deficiency would help patients to acquire adaptive strategies effectively (6). However, most of the children develop an awareness of their weakness in schools (21). Furthermore, children have recalled their difficulties after being diagnosed as CVD (22). Our cohort of school children has reported difficulties in separation of cooked food and uncooked food and colour setting in digital screens. It has been observed that CVD students face difficulties in subjects including food technology, science and geography where colour is extensively used (21). However, a study done in 1958 on British birth control has concluded that CVD children perform par with their healthy peers educationally (23). The same study has also shown that the risk of unintentional injuries did not associate with CVD. However, the increasing use of colour in education in the recent past raises concerns for CVD children. Furthermore, as shown in this study, education activities based on digital screens (smart classrooms) may cause difficulties for CVD (24). Increased usage of online teachinglearning activities after the emergence of COVID-19 is a matter of concern on this regard.

Awareness of the disease plays a vital role. Under reporting of the difficulties may be associated with a lack of awareness (25). It has been suggested that awareness of CVD helps to identify and develop corresponding coping strategies (7). In our cohort, there was no significant difference in parent-reported difficulties between the normal and affected children. Furthermore, only one parent was aware of the child's CVD status. In existing health or education system in Sri Lanka, there is no place to detect CVD patients. The authors would like to suggest screening for CVD at school medical inspection and incorporating CVD in the curriculum for preschool and primary grade teachers.

Barry et al. have shown that a significantly higher negative impact on the quality of life of CVD patients than normal-sighted controls with regards to confusion over colour in various aspects of life (26). Harris et al. showed that CVD 
handicapped to engage in sports activities such as cricket (27). We have reported the high percentage of intimidation related to CVD in this study. The intimidation related to CVD may further affect the quality of life and psychosocial developments in affected children.

At present, there is no consensus on which colour test is the most complete. Therefore, it is advisable to use at least two tests to ensure diagnoses. The Ishihara test is the most widely used screening test for CVD and a very sensitive screening test (28). The panel tests, including the Farnsworth Panel D-15 and Farnsworth-Munsell 100-hue tests, are much more accurate in classifying colour deficiency (29). The Anomaloscope is considered as the "gold standard" for colour vision testing (30). The complexity in usage, and time consuming nature has limited the usage of it in clinical practice.

\section{Limitations}

CVD in the group studied was not confirmed by a second test. Furthermore, the small number of patients with color defects studied in this study is inadequate for a generalised conclusion of their difficulties.

\section{Conclusion and recommendation}

CVD is not uncommon in the Galle education zone, Sri Lanka. The affected children in the two schools studied face difficulties in their day-to-day life due to their defects. A large population-based study is needed to determine the ethnicity-specific prevalence and impact of the CVD in Sri Lanka.

\section{Acknowledgement}

We thank Dr. J.K.M.K Rasika and Mrs. B. Keebiyahetti for the support extending at collecting data.

\section{Conflicts of interest}

The authors declare that there is no conflict of interest.

\section{References}

1. Post RH. Population differences in red and green color vision deficiency: A review, and a query on selection relaxation. Social Biology, 1982; 29(3-4): 299-315.

2. Mann I, C Turner, Color vision in native races in Australasia. Am J Ophthalmol. 1956; 41(5): 797-800.

3. Brown, A.M. and D.T. Lindsey, Color and language: worldwide distribution of Daltonism and distinct words for "blue". Vis Neurosci. 2004; 21(3): 409-412.

4. John Dalton's discovery of his colour blindness. Appl Opt. 1977; 16(2): 520

5. Mollon JD, LR Cavonius. The Lagerlunda collision and the introduction of color vision testing. Surv Ophthalmol. 2012; 57(2): 178-194.

6. Cole BL. The handicap of abnormal colour vision. Clin Exp Optom. 2004; 87(4-5): 258-275.

7. Chan XBV, SMS Goh, NC Tan. Subjects with colour vision deficiency in the community: what do primary care physicians need to know?. Asia Pacific Family Medicine. 2014; 13(1): 10 .

8. Spalding JA, BL Cole, FA Mir. Advice for medical students and practitioners with colour vision deficiency: a website resource. Clin Exp Optom. 2010; 93(1): 39-41.

9. Hasrod N, A. Rubin. Defects of colour vision: A review of congenital and acquired colour vision deficiencies 2016, 2016; 75(1).

10. Birch J. Worldwide prevalence of red-green color deficiency. J Opt Soc Am A Opt Image Sci Vis. 2012; 29(3): 313-320.

11. Karunanayake A, Egodage UK, Wijekoon WMCD, Uluwitiya SMM, Trimavithana MG. Prevalence of the colour blindness and its impact on their education among undergraduates of University of Ruhuna. Galle, Sri Lanka: Galle Medical Journal. Annual Scientific Session of Galle Medical Association. 2013;18(2): 53.

12. Ganga M Jayasena, Maduwanthi M Dissanayake, Mangala Gunatilake, Koddippili IIH, Galappaththi NC. Effects of colour blindness in medical students in the Faculty of Medicine, Colombo, Sri Lanka in $7^{\text {th }}$ Federation of Asian Oceanian Physiological Societies Congress held in Taipei, Taiwan. 2011:351. 
13. Fareed M, MA Anwar, M Afzal. Prevalence and gene frequency of color vision impairments among children of six populations from North Indian region. Genes Dis. 2015; 2(2): 211-218

14. Navjot Kaur KS, Comparative review of color blindness in different ethnic populations. Journal of Evolution of Medical and Dental Sciences. 2013; 02(36): 6977-6981.

15. Shrestha RK, et al., Color vision defects in school going children. JNMA J Nepal Med Assoc. 2010; 50(180): 264246.

16. Reimchen TE. Human color vision deficiencies and atmospheric twilight. Soc Biol. 1987.34(1-2): 1-11.

17. Sharpe LT, et al., Advantages and disadvantages of human dichromacy. JVis. 2006; 6(3): 213-223.

18. Morgan MJ, A Adam, JD Mollon. Dichromats detect colour-camouflaged objects that are not detected by trichromats. Proc Biol Sci. 1992; 248(1323): 291-295.

19. Jägle H, et al., Visual acuity and X-linked color blindness. Graefe's Archive for Clinical and Experimental Ophthalmology. 2005; 244(4): 447.

20. Gegenfurtner KR, FA Wichmann, LT Sharpe, The contribution of color to visual memory in X-chromosomelinked dichromats. Vision Res. 1998; 38(7): 1041-1045.

21. Sullivan K. Colour-blind children. Special Educ Needs. 2011; 12: 21-23.

22. Steward JM, BL Cole, What do color vision defectives say about everyday tasks? Optom Vis Sci. 1989; 66(5): 288-295.
23. Cumberland P, JS Rahi, CS Peckham. Impact of congenital colour vision deficiency on education and unintentional injuries: findings from the 1958 British birth cohort. BMJ. 2004: 329(7474): 1074-1075.

24. Mashige KP. Impact of congenital color vision defect on color-related tasks among schoolchildren in Durban, South Africa. Clinical Optometry. 2019; 11: 97-102.

25. Spalding JA. Colour vision deficiency in the medical profession. Br J Gen Pract, 1999; 49.

26. Barry JA, et al., Development and validation of a questionnaire assessing the quality of life impact of Colour Blindness (CBQoL). BMC ophthalmology, 2017; 17(1): 179.

27. Harris RW, BL Cole, Abnormal colour vision is a handicap to playing cricket but not an insurmountable one. Clin Exp Optom. 2007; 90(6): 451-456.

28. Birch J, Identification of red-green colour deficiency: sensitivity of the Ishihara and American Optical Company (Hard, Rand and Rittler) pseudo-isochromatic plates to identify slight anomalous trichromatism. Ophthalmic Physiol Opt. 2010; 30(5): 667-671.

29. Pandey N, AK Chandrakar, ML Garg. Tests for color vision deficiency: Is it time to revise the standards? Indian JOphthalmol. 2015; 63(9): 752-753.

30. Fanlo Zarazaga A, J Gutiérrez Vásquez, V Pueyo Royo. Review of the main colour vision clinical assessment tests. Arch Soc Esp Oftalmol. 2019; 94(1): 25-32. 